\title{
DECÁlOGO DA ESCOLA COMO ESPAÇO DE PROTEÇÃO SOCIAL: CONSOLIDANDO A FUNÇÃO SOCIAL DA ESCOLA COMO ESPAÇO DEMOCRATIZANTE
}

\author{
DECALOGUE OF THE SCHOOL AS A SPACE FOR SOCIAL \\ PROTECTION: CONSOLIDATING THE SOCIAL FUNCTION OF THE \\ SCHOOL AS A DEMOCRATIZING SPACE
}

\begin{abstract}
Emina Márcia Nery dos Santos Doutora em Ciências Sócio Ambientais (UFPA). Atualmente é professora Titular da UFPA e coordena o Grupo de Estudos em Educação em Direitos Humanos - GEEDH vinculado ao Programa de Pós-graduação em Currículo e Gestão da Escola Básica (PPEB)

emina@ufpa.br
\end{abstract}

\begin{abstract}
Francisco Willams Campos Lima
Doutor em Educação (UFPA). Professor efetivo da Universidade do Estado do Pará (UEPA) e da educação básica no município de Ananindeua - PA, onde atualmente exerce o cargo de Presidente do Conselho Municipal de Educação. willamscampos@yahoo.com.br
\end{abstract}

\author{
iD Cassio Vale \\ Doutorando em Educação (EducaNorte / UFPA). \\ cassiovale07@yahoo.com.br
}

\begin{abstract}
Resumo: Neste artigo, sistematizam-se elementos estruturantes da escola como ambiente que se consolida como espaço de proteção de direitos e de valorização da diversidade, relevando que tal entendimento é condição de possibilidade de sua constituição como espaço formativo de empoderamento de crianças e adolescentes e propiciador de sua elevação a sujeitos de direitos e protagonistas de sua própria história. O texto objetiva reafirmar a premissa da educação em Direitos Humanos como condição para o fortalecimento de relações sociais baseadas na inclusão social e na democracia participativa, ressignificando, portanto, sua secular função social, baseada na racionalização de conteúdos formativos hegemônicos adequados aos interesses dirigentes. $\mathrm{O}$ artigo resulta de estudo documental dos principais referenciais normativos da política educacional brasileira pós Constituição Federal, e bibliográfico, com base em autores que pesquisam e argumentam em torno dos valores humanistas, de inclusão social e democracia política como Touraine (1992; 1994; 1996; 1998), Estévão (2004), Cury (2005) e Freire (1992). Dessas análises, defende-se a tese segundo a qual a escola - como instituição política e social contraditória, pois reprodutora de arranjos não menos contraditórios presentes na sociedade - pode se assentar como lugar privilegiado para toda essa complexa dinâmica, formando universalmente as pessoas para que possam ocupar os espaços políticos e levar ao Estado suas demandas plurais como conteúdo das políticas públicas.
\end{abstract}

Palavras-chave: Educação em direitos humanos. Escola como espaço protetivo de direitos. Escola e democracia.

Abstract: The paper systematizes structuring elements of school as an environment strengthened as a space for rights protection and diversity appreciation, which reveals such understanding is a condition of its own constitution as a formative space towards empowerment of children and teenagers, and how it allows their transformation into subjects of rights and protagonists of their own stories. The text aims to reaffirm the premise of human rights education as a condition for strengthening of social relations based on social inclusion and participative democracy, as it is a process which gives a new meaning the school secular social function, based on the rationalization of hegemonic formative contents which are suitable to leading interests. The paper results from document analysis of the main normative references of Brazilian educational research post-Constitution, as well as bibliographic analysis which considers authors who have researched about and argued for human values, social inclusion as political democracy, authors such as Touraine (1992; 1994; 1996; 1998), Estévão (2004), Cury (2005) e Freire (1992). The analyzes carried out allow a thesis defense according which the school is taken as a political and contradictory institution, due to even more contradictories reproducing accounts, therefore the same school may be placed in a privileged spot for all this dynamic, since it forms people universally for occupying political spaces and for bringing up to the State their plural demands as the very content of public policies.

Keywords: Human rights education. School as protective space for rights. School and democracy.

Para citar - (ABNT NBR 6023:2018)

SANTOS, Emina Márcia Nery dos; LIMA, Francisco Willams Campos; VALE, Cassio. Decálogo da escola como espaço de proteção social: consolidando a função social da escola como espaço democratizante. Eccos - Revista Cientifica, São Paulo, n. 54, p. 1-18, e8338, jul./set. 2020. Disponível em: https://doi.org/10.5585/eccos.n54.8338. 


\section{Introdução}

Neste artigo, sistematizamos elementos estruturantes da escola como ambiente que se consolida como espaço de proteção, relevando que somente em um espaço valorativo da diversidade como condição educativa pode-se empoderar crianças e adolescentes, transformando-os em sujeitos de direitos e protagonistas de sua própria história. Trata-se da premissa de educar em Direitos Humanos como condição para o fortalecimento de relações sociais democráticas, fundamento que ressignifica a função social da escola. Premissa reforçada pelo Plano Nacional de Educação em Direitos Humanos, cuja concepção contemporânea "incorpora os conceitos de cidadania democrática, cidadania ativa e cidadania planetária, por sua vez inspiradas em valores humanistas e embasadas nos princípios da liberdade" (BRASIL, PNEDH, 2007).

Por função social da escola, nesse contexto, entendemos o compromisso políticoinstitucional que ela intencionalmente assume em dado contexto histórico no processo de preparação das pessoas para viver em sociedade. Trata-se de uma tarefa eivada de conteúdo ideológico, presente tanto no plano das orientações legais da política educacional brasileira quanto, fundamentalmente, no paradigma de formação dos profissionais da educação assumido pelas agências formadoras a partir de diretrizes nacionais de formação.

Problematizamos a função que a escola assume como instituição da formação integral do sujeito. Para tal, partimos da premissa de que esses sujeitos se constituem, reconhecendo-se e agindo como tal, a partir de sua individualidade, sendo capazes de atuar como agentes de transformação, de resistência e, por isso, em condição de "compor a democracia, entendida como 'reencantamento do mundo', colocando-se como tripulante ou como viajante, que se portará como protagonista ou apenas se deixará conduzir" (TOURAINE, 1994, p. 214). Desse princípio deriva um segundo, tão ou mais importante que o primeiro, que é a alteridade, ou seja, a empatia com a construção individual do outro como sujeito a partir de sua individualidade, desejos e perspectivas de vida, já que, ainda para Touraine (op.cit., p. 240), "é pela relação ao outro como sujeito que o indivíduo deixa de ser um elemento de funcionamento do sistema social e se torna criador de si mesmo e produtor da sociedade."

Nesse aspecto, ao se firmar como espaço institucional onde se formam valores para a convivência democrática a partir dos Direitos Humanos, o ambiente escolar se torna referência de lugar que educa e não somente instrui. E o faz potencializando culturas, recriando e reposicionando saberes, encorajando posições políticas plurais, efetivando direitos, respeitando o estranho, ampliando cidadania e valorizando cada um e cada uma a partir de seus interesses, 
desejos e necessidades. A finalidade é a formação de mulheres e homens capazes de se perceberem como sujeitos que merecem ser tratados com dignidade e que, por isso, possuem o direito de serem formados para participarem ativamente e com plenitude dos rumos trilhados pela sociedade, em uma perspectiva democrática e democratizante. Importa elucidar que utilizamos o conceito de sujeito presente em Alan Touraine (1992, p. 262), definido como sujeito existencial, "um sujeito do mundo, que se sente responsável por si mesmo e pela sociedade."

Defendemos, portanto, a tese de que a escola é instituição política e contraditória, pois reprodutora das complexas relações e arranjos de poder presentes na sociedade, ao mesmo tempo em que pode se assentar como lugar privilegiado para toda essa formação, consubstanciando valores que possibilitem a legitimação de outro papel social para a instituição, diferentemente daquele assumido socialmente desde o século passado e que, segundo Arendt (2005, p. 83), "prioriza as atividades do trabalho e do consumo; que deseja avidamente a novidade pela novidade, orientando-se apenas pelo futuro imediato".

Assim, a função da escola, enquanto instituição mediadora da relação entre o ser humano com o mundo tem atuado como propiciadora dessa perpetuação. Como resultado disso, tornamos rasteiras e superficiais nossas modernas utopias de felicidade, que passam a se basear não mais na construção moral da nossa humanidade, e sim na nossa capacidade de consumir muito e rapidamente para a satisfação, também imediata, de nossos desejos e prazeres. Barateamos nossa condição de dignidade, bastando-nos a mera sobrevivência, desde que tenhamos satisfeitos os nossos desejos. Não nos interessa a utilidade pública dos espaços públicos, isto é, não nos interessa a dignidade do outro, a solidariedade ao direito do outro ou à sua dor.

Essa tendência ganha corpo em todos os níveis e modalidades de nosso processo educativo formal, dando-nos a sensação de que a escola - como espaço sustentável e utópico de construção de um paradigma inclusivo em direitos humanos - esvaiu-se, e com ela todas as grandes utopias da modernidade. Pode-se, portanto, contrariar o atual paradigma racionalista de educação que ameaça a emergência do sujeito em todo o seu potencial criativo. Para tal, o ambiente escolar, visto como educativo, deve reunir condições em torno das quais a dignidade, enquanto princípio pedagógico seja enfatizada em todas as atividades propostas e em todos os espaços constitutivos da escola: nas práticas pedagógicas, na gestão, no currículo, no projeto pedagógico - enfim, na sua totalidade organizativa.

Resolvemos, para isso, reunir essas condições em um total de dez elementos, que nesse estudo bibliográfico denominamos Decálogo da Escola Protetiva. Da mesma forma, desde já 
explicamos que os indicadores aqui mencionados se referem a uma organização didática de ideias que reputamos como imprescindíveis para que se transforme o paradigma de escola da atualidade, baseado na racionalização de saberes hegemônicos que configura, de acordo com Neves (2005, p. 15), um paradigma educacional consubstanciador do "consenso sobre os sentidos de democracia, cidadania, ética e participação adequados aos interesses privados do grande capital nacional e internacional”.

No entanto, há interdependência entre cada um desses pressupostos e a condição para entendê-los é a cumulatividade entre eles. Não se pode deixar de analisá-los conjuntamente, para que a escola se afirme a partir de outro protagonismo social. Da mesma forma, vale a pena registrar que não há hierarquia de importância ou de maior ou menor funcionalidade entre os aspectos. Complementares entre si, somente ensejam a possibilidade de consolidação de uma escola protetiva a partir do momento em que atuam concomitantemente, aliados a um princípio comum: a garantia da dignidade de cada uma e cada um que compõe a escola.

\section{Decálogo da escola como espaço de proteção social}

Passaremos à classificação das condições estruturantes que podem potencializar a escola como espaço de proteção social dos direitos de crianças e adolescentes.

\section{Universalidade e obrigatoriedade}

O primeiro elemento escolhido para sistematizar a concepção da escola como espaço de proteção foi a problematização acerca da sua relação orgânica com uma sociedade cujos indicadores de densidade democráticos sejam incontroversos. Parte-se da premissa de que somente em ambientes intensamente democráticos podem-se conceber instituições que atuem com base em relações nas quais o direito constitua a tônica de relevância e seja concebido distributivamente. Refutamos, portanto, relações baseadas em favorecimentos e privilégios políticos. De acordo com Lima e Silveira (2016, p. 49), “[...] educar em direitos humanos é fundamental porque tanto é uma garantia de que o direito à educação se materialize, quanto salvaguarda que, por meio desse direito, seja aperfeiçoada e protegida a democracia num país."

Defendemos a oferta e aquisição de uma educação formal de qualidade, concebida como dever do Estado e disponibilizada de modo obrigatório e universal. Esse processo deve servir para capacitar o indivíduo a exercitar sua cidadania ativa, por meio da expressão de seus desejos privados e de seus projetos coletivos como condição estruturante para o desenvolvimento da pessoa humana, para o respeito e reconhecimento dos diferentes projetos de vida e dos valores 
e perspectivas de vida alheias. A escolarização deve servir como base para a aquisição/construção das condições básicas de vida, para o exercício da crítica, da criatividade e da liberdade de ideias e para o reconhecimento da diversidade e dos direitos. A esse respeito, Cury (2005, p. 486) afirma que

O direito à educação parte do reconhecimento de que o saber sistemático é mais do que uma importante herança cultural. Como parte da herança cultural, o cidadão tornase capaz de se apossar de padrões cognitivos e formativos pelos quais tem maiores possibilidades de participar dos destinos de sua sociedade e colaborar na sua transformação.

Na política educacional brasileira, a oferta obrigatória e universal da educação traduz iniciativa política bastante recente, mais precisamente a partir dos anos 2000 porque tal perspectiva somente começou a ser tratada como base conceitual das iniciativas de ações públicas educacionais na década de 1990 em âmbito internacional e o Brasil não acompanhava tal perspectiva em função de governos defensores de um projeto neoliberal em toda a década, o que começou a ter mudança com a ascensão de um governo dito pós-neoliberal em 2003 que estava mais voltado para a institucionalização de ações que visavam à ampliação do espectro de cidadania das camadas populares e por meio da ampliação do protagonismo estatal como provedor dos direitos humanos mais fundamentais, como nos indica Pochmann (2013, p. 154):

essa inversão de projeto de desenvolvimento da nação brasileira se deu a partir da opção de conceder forte ênfase às políticas sociais. Isso implicou romper com a perspectiva dos governos neoliberais dos anos de 1990 [...] e o Brasil conseguiu voltar a permitir a ascensão social para milhões de brasileiros, após mais de duas décadas de congelamento das oportunidades educacionais, de renda e de ocupação.

Com isso, foram ampliadas de forma bastante significativa as oportunidades de acesso e permanência dos segmentos mais vulneráveis da população no sistema educacional brasileiro, sujeitos cuja maior fragilidade era a financeira, assim inseridos em um modelo que extrapolava a implementação de políticas assistencialistas. Foram institucionalizadas políticas públicas de acesso e permanência aos até então ignorados pelas políticas meritocráticas que há anos privilegiavam as elites históricas e excluíam os mais pobres (GENTILI; OLIVEIRA, 2013). Ressignifica-se o sentido histórico de obrigatoriedade da oferta a partir do reconhecimento de que, além de obrigatório, deveria ser para todos, sendo tal premissa entendida como "a mais estruturante possibilidade de ampliação de uma esfera de direitos historicamente negada ao povo brasileiro." (op.cit., p. 254)

Esse movimento amplia o financiamento público das políticas educacionais, as quais, na mesma proporção em que qualificam a presença das pessoas na escola, são capazes de alterar a fisionomia da sociedade brasileira. São políticas que garantem a efetividade do direito, 
asseguram sua oferta aos que precisam e reparam as consequências da ausência do Estado na vida de milhares de brasileiros ${ }^{1}$.

\title{
2 Democrática
}

A escola precisa se consolidar como o lugar onde são formados valores para o fortalecimento da cultura democrática, pois a "educação na democracia é uma tarefa dirigida ao desenvolvimento de uma personalidade que faz do diálogo, da confrontação das ideias e da participação os elementos de seu processo formativo presente" (RAYO, 2004, p. 89). Utilizamos o conceito de democracia constante no Plano Nacional de Educação em Direitos Humanos (BRASIL, 2007, p. 24), que o entende como

\begin{abstract}
regime alicerçado na soberania popular, na justiça social e no respeito integral aos direitos humanos, é fundamental para o reconhecimento, a ampliação e a concretização dos direitos. Para o exercício da cidadania democrática, a educação, como direito de todos e dever do Estado e da família, requer a formação dos (as) cidadãos(ãs).
\end{abstract}

Sobre ambientes democráticos, ressalva-se a classificação de Silva (2008), a partir de Touraine (1998), sobre as três dimensões da democracia: a primeira destaca a necessidade incontroversa do reconhecimento dos direitos humanos fundamentais, reconhecimento capaz de limitar o poder de atuação discricionária do Estado, das igrejas e de qualquer outra instituição que se pretenda unificadora de valores e padrões de comportamento; a segunda dimensão trata da consciência de cidadania, baseada na atuação da coletividade, fundada no direito e no protagonismo dos sujeitos com responsabilidade na vida pública; e a terceira e última dimensão da democracia reside na pluralidade dos sujeitos que formam a sociedade civil, os quais exigem que a democracia seja representativa e pluralista.

Partimos da premissa inconteste, portanto, de que a participação das pessoas em ambientes públicos coletivos pode aperfeiçoar o senso de democracia e a postura respeitosa a elas em relação ao direito como conquista universal. Ao conjunto desses lugares que potencializam a cultura da participação pública, Putnam (1996) denomina 'região cívica'. Segundo o autor, quanto maior a participação das pessoas em espaços públicos de interação, maior sua densidade cívica, valendo o mesmo raciocínio para as menos cívicas, que são

\footnotetext{
1 Para que essas observações não sejam interpretadas como retóricas ou mera propaganda política, muitas iniciativas podem ser citadas: implementação do Fundo de Manutenção e Desenvolvimento da Educação Básica e de Valorização do Magistério (FUNDEB); Piso Salarial Profissional Nacional (PSPN); Democratização do Ensino Superior por meio das políticas de cotas e Programa Universidade para Todos (PROUNI); Ampliação da obrigatoriedade escolar do Ensino Fundamental para a Educação Básica a partir da Emenda Constitucional n ${ }^{\circ}$ 9; Plano Nacional de Formação de Professores da Educação Básica (PARFOR).
} 
caracterizadas pela baixa densidade participativa da comunidade em espaços públicos de decisão.

Essa proposição potencializa nossa argumentação a partir de duas assertivas: a primeira, de que todo espaço coletivo constitui um espaço de formação, no qual a educação se processa por ser prática social da qual não estamos desvinculados; a segunda reafirma a primeira, já que a escola é espaço de interação e, por isso, intencionalmente formativo, e, se assim o é, efetivase como lugar capaz de ampliar o desempenho cívico ${ }^{2}$, aqui referenciado como desempenho de cidadania ativa, ou, nos dizeres de Dallari (2016, p. 18), uma aprendizagem referente a

um conjunto de direitos que dá à pessoa a possibilidade de participar ativamente da vida e do governo de seu povo. Quem não tem cidadania está marginalizado ou excluído da vida social e da tomada de decisões, ficando numa posição de inferioridade dentro do grupo social.

O aprendizado democratizante possui várias finalidades, mas a principal é qualificar a vida das pessoas. Percebe-se a relação direta de participação política com empoderamento e reconhecimento de direitos como lógica das relações entre as pessoas, ao passo que a baixa densidade participativa remete ao frágil espírito democrático.

Ressaltamos que se a escola assumir sua função cultural e política de cuidar e educar na perspectiva da formação universal e cidadã, ela se converterá em ambiente privilegiado para ampliar a densidade democrática das relações em sociedade.

\section{Laica}

Condição e ao mesmo tempo resultado de um Estado destituído de religião oficial, somente a escola laica é capaz de se posicionar criticamente em torno da produção científica do conhecimento. A religião não pode constituir referência para a compreensão do mundo nem para a sustentação de valores, atitudes ou comportamentos. De acordo com Luis Antonio Cunha (2017, p. 18),

no Estado laico a moral coletiva, particularmente a que é sancionada pelas leis, deixa de ser tutelada pela religião, passando a ser definida no campo político, estritamente. Isso quer dizer que as leis, inclusive as que têm implicações éticas ou morais, são elaboradas com a participação de todos os cidadãos, sejam eles religiosos ou não. $\mathrm{O}$ Estado laico não pode admitir que instituições religiosas imponham que tal ou qual lei seja aprovada ou vetada, nem que alguma política pública seja mudada por causa de valores religiosos. Todavia, o Estado laico não pode desconhecer que os religiosos de todas as crenças têm o direito de influenciar a ordem política, fazendo valer, tanto quanto os não crentes, sua própria versão do que é melhor para toda a sociedade, renunciando a exercer tutela moral sobre ela. Nas democracias representativas pode

\footnotetext{
${ }^{2}$ Que em nada se aproxima de um civismo patriótico, baseado na ideia do 'amor pela pátria', ou do civismo moral, como um conjunto de regras universais que têm a finalidade de regular o comportamento do indivíduo na sociedade; tem, sim o sentido de aprendizado de valores que insere homens e mulheres no mundo público, como protagonistas nos espaços de decisão e nas esferas políticas do meio onde estão inseridos. 
haver tensão entre o caráter laico do Estado e a atuação de parlamentares eleitos com base em plataformas religiosas. A prevalência de um ou de outro pólo dessa tensão depende da conjuntura política e, principalmente, do lugar ocupado pelos partidos no campo político de cada país.

Sendo assim, o ambiente escolar precisa estar pautado em argumentações racionais para explicar a sociedade e as relações que nela se desenvolvem, evitando, a todo custo, o enfrentamento das questões que tenham como base a orientação religiosa dos estudantes e de seus familiares. A liberdade religiosa, portanto, além de constituir direito consagrado constitucionalmente, é indicador de que o projeto de educação se pauta no respeito à dignidade das pessoas, não devendo ser tratado como elemento segregador ou discriminatório, muito menos como enunciado explicativo em desacordo com o desenvolvimento das ciências.

A liberdade de expressão religiosa e de culto deve ser elemento de valorização das etnias, das diversidades, dos valores e costumes e, fundamentalmente, das diferentes formas que os seres humanos escolhem para se comunicar, ou não, com o transcendente. Lembre-se que, de acordo com a Lei de Diretrizes e Bases da Educação (Lei 9394/1996), o ensino religioso, embora de oferta obrigatória na escola pública, constitui disciplina optativa do fluxo curricular da educação básica. Nesse sentido, a presença da religião na escola se dá pelo seu caráter científico, enquanto ensino de história e/ou ciências da religião, e não de credo ou doutrina religiosa, por se reconhecer que, ao longo da história da humanidade, muitas foram as formas e modalidades que homens e mulheres inventaram para conduzir sua espiritualidade, aos que assim creem, e ao se relacionar com a natureza, aos que assim preferem. Esse conteúdo é importante para que se tenha conhecimento de todas essas culturas, sem jamais se ter a pretensão de eleger uma cultura como mais importante. Prima-se pelo respeito ao direito à diferença.

$\mathrm{Na}$ escola, o conteúdo religioso que pretende ser unificador de concepções de mundo, constituinte de pauta única de valores e capaz de conduzir a uma direção intelectual e moral unificada, deve ser condenado como proselitismo e como imposição cultural. Não é possível se conceber uma escola democratizante se essas instituições não forem laicas e estiverem sob o domínio de qualquer matriz de ideologia religiosa.

\section{Inclusiva}

A finalidade de caracterizar a escola protetiva como inclusiva extrapola a concepção de inclusão de pessoas com deficiência. Refere-se também à inclusão como demanda política de acolhimento dos diversos mundos que compõem o espectro social, buscando superar a dimensão imprescindível, mas restrita, da inclusão das pessoas com deficiência. Embora o 
atendimento escolar a esse segmento vulnerável da população ainda não tenha sido universalizado, acreditamos que já foram dados passos largos, notadamente a partir de todo o marco regulatório que normatiza a política de inclusão.

Nesse sentido, a escola atual trata os alunos desiguais a partir de uma igualdade baseada na justiça formal, na norma constituída, na lei positivada. Dessa forma, exige qualidades que são desigualmente distribuídas a partir de suas origens de classe. Bourdieu (1998) nos indica essas qualidades a partir do capital cultural dominante e da consequente relação entre o indivíduo, a cultura e o saber. Com essa dinâmica, a escola inclui no ingresso, mas reproduz diretrizes sutis de exclusão na permanência, reproduzindo desigualdades:

\footnotetext{
Esta problematização das desigualdades transporta de modo mais explícito para a escola, leva-me pela sua importância a convocar aqui, ainda que sumariamente, o pensamento de $P$. Bourdieu, quando analisa as funções de reprodução e de legitimação das desigualdades sociais que a escola cumpre, nomeadamente pela transmissão de uma cultura imposta e portadora de um discurso socialmente neutro, universal e não arbitrário (...) a justiça ou a equidade formal que a escola apregoa, reproduz de facto, embora de forma velada, uma pluralidade de formas de injustiça, situação que se agrava na medida em que a escola possibilita a acumulação e convertibilidade das diferentes formas de capital nomeadamente pela conversão do capital sócio-econômico em capital cultural sob a bandeira do mérito. (ESTEVÃO, 2004, p. 43-44, grifos nossos)
}

Obviamente, a escola, a partir desse raciocínio, tem facilidade de incluir os que não somente compartilham com os seus valores formais, porque originários deles. A inclusão na escola como espaço protetivo de direitos parte da premissa da inclusão como reconhecimento da pluralidade em todas as suas dimensões relacionais e de gestão. Trata-se de invocar o conceito de justiça social - ou justiça distributiva - para a "justiça curricular, que atenda aos modos pelos quais o currículo concede e retira o poder, autoriza e desautoriza, reconhece e desconhece diferentes grupos de pessoas e seus conhecimentos e identidades." (op.cit., p. 45, grifos nossos) Para esse autor, a inclusão pela via da justiça curricular deve ser implementada a partir de três princípios gerais: a) focalização nos interesses dos mais desfavorecidos, como possibilidade de a escola servir como transmissora de conhecimentos capazes de gerar seu protagonismo social, sua cidadania ativa e seu empoderamento; b) participação e currículo comum, entendendo currículo como território de disputa e poder, consolidando a matriz participativa como implementadora de processos democráticos equânimes e sustentáveis; e c) a consideração da igualdade como produção histórica, situada no tempo e no espaço político construído por desiguais e diferentes, igualdade como marcador de classe e proposta de sociedade liberal e equidade como sua reverberação em democracias com justiça social. 


\section{Integral}

Como condição indispensável à ampliação da formação cidadã, a escola precisa oferecer educação integral em tempo integral para alunos e professores. Partimos do pressuposto de que ampliar a presença de estudantes e professores na escola ao longo dos dias aumenta as perspectivas de seu contato com valores que contribuem para a solidariedade humana, a valorização do diferente, a criação de espaços e tempos que potencializem o intercâmbio de ideias e a inclusão social nas suas mais variadas formas e modalidades.

A escola de tempo integral, embora seja uma demanda ainda não efetivada pelo Estado brasileiro, constitui necessidade antiga na história da nossa educação pública. Sobre sua origem, destaca-se o seguinte:

Em 1950, Anísio Teixeira, inspirado na teoria sobre reconstrução da experiência e no conceito de educação de John Dewey, que afirmava a necessidade de criamos oportunidades para que a criança e o adolescente vivenciassem, através da experiência, o modo de vida democrático para assegurarmos uma sociedade democrática, idealizou uma "pequena universidade infantil". As diferentes atividades seriam distribuídas por vários prédios constituindo-se, assim, num Centro, o Centro Educacional Carneiro Ribeiro (CECR) [...] Assim Anísio Teixeira se expressou no discurso de inauguração do Centro: Tive, então oportunidade de ponderar que, entre nós, quase toda a infância, com exceção de filhos de famílias abastadas, podia ser considerada abandonada. Pois, com efeito, se tinham pais, não tinham lares em que pudessem ser educados e se, aparentemente tinham escolas, na realidade não as tinham, pois as mesmas haviam passado a simples casas em que as crianças eram recebidas por sessões de poucas horas, para um ensino deficiente e improvisado. No mínimo, as crianças brasileiras, que logram frequentar escolas, estão abandonadas em metade do dia. E este abandono é o bastante para desfazer o que, por acaso, tenha feito a escola na sua sessão matinal ou vespertina. Para remediar isso, sempre me pareceu que deveríamos voltar à escola de tempo integral. (CASTRO; LOPES, 2011, p. 263, grifos nossos)

Origina-se, portanto, como espaço demarcado pela função do cuidar, fortalecendo a formação humana das suas crianças e adolescentes. Embora inexistente de forma conceitual, já se abordava a perspectiva de a escola atuar em sua função social, como espaço protetor de crianças e adolescentes em situação de rua, durante parte do seu dia. Peca em restrição conceitual, por se tratar de uma concepção meramente compensatória de educação de tempo integral, baseada no fato da existência de falha na educação familiar. Entendemos ser essa uma das tarefas da escola, mas não a única. Compreendemos que essa função, aliada à complementação do currículo escolar com atividades esportivas, de lazer, artísticas e outras que considerem a integralidade da personalidade do ser humano constitui o que hoje se defende, majoritariamente, como paradigma de educação integral, não somente de educação de tempo integral, como diferenciam Galian e Sampaio (2012, p. 404, grifo nosso): 
Impossível iniciar uma reflexão sobre a crescente valorização da ideia de uma educação em tempo integral sem mencionar a necessária diferenciação entre esta noção e a de uma educação integral. Trata-se de falar em uma formação integral do indivíduo, neste último caso, e de ocupação ampliada do tempo na escola, no primeiro. Não que uma coisa não possa estar relacionada a outra, mas uma discussão séria sobre o tema exige enfrentar algumas questões, tais como: ampliar o tempo de permanência das crianças na escola visa sua formação integral ou o preenchimento do tempo com mais atividades, de cunho escolar ou não, a fim de mantê-las ocupadas e distantes das ruas? A grande questão, portanto, é o que se pretende com isso? E quais as implicações dessa discussão para o currículo escolar?

É importante analisar a que serve uma formação integral, em que conteúdos se baseia e em quais valores sustenta seu projeto de mundo e de sociedade. Salientamos que a formação integral aqui proposta como condição para a efetivação da escola como espaço protetivo baseiase nessa problematização. Caso contrário, amplia-se o tempo de uma escola que não serve aos interesses das classes populares - e, desse modo, a formação integral que emancipa, empodera e forma para a cidadania ativa continua como utopia distante. Aponta-se a necessidade de se implantar uma escola de tempo integral que efetivamente se ocupe com a formação integral, para que crianças e adolescentes decidam o caminho a seguir e que a escola, ao protegê-los, ajude-os nessa construção.

\section{Centrada no estudante}

Parte-se da premissa de que todas as atividades, desde o planejamento pedagógico até a orientação das práticas pedagógicas, devem sobrelevar como elemento de centralidade o aluno, seu desenvolvimento e sua dignidade, seu desenvolvimento integral como pessoa. Entende-se que cabe à escola, por meio de seus agentes, disponibilize todos os seus recursos e insumos para que sejam satisfeitas as necessidades essenciais dos estudantes em todas as etapas que definem o processo de ensino e aprendizagem.

Para tal, conforme Campbell (2010, p. 25-30), devem ser resguardados como objetivos institucionais: o respeito aos marcos legais estabelecidos em torno dos direitos dos estudantes: Constituição Federal, Lei de Diretrizes e Bases da Educação, Estatuto da Criança e do Adolescente, Diretrizes Curriculares correspondentes ao nível de ensino; a formação progressiva da autonomia dos estudantes; a formação desses sujeitos para que sejam capazes de constituir uma autoimagem positiva, ampliando sua autoestima; a capacidade para que cada um enfrente situações de conflito, com vistas ao exercício do respeito ao próximo, criança ou adulto; o desenvolvimento da capacidade de aprender com efetividade, pelo domínio pleno da leitura, interpretação e desenvolvimento das diversas linguagens que compõem o repertório comunicacional da sociedade atual; formação de comportamentos atitudinais, éticos e estéticos; 
fortalecimento dos vínculos familiares, seja qual for o modelo familiar no qual se insere o aluno, assim como dos laços de solidariedade humana; potencializar o posicionamento crítico, responsável, consequente e construtivo dos educandos em diferentes situações; e, por fim, conhecer, valorizar e respeitar a pluralidade ideológica que nos organiza enquanto nação.

\section{Sustentável}

Essa característica decorre de a escola ser vista e defendida pela comunidade na qual se insere socialmente como instituição ${ }^{3}$, na qual sua atuação e o trabalho que executa sejam vistos como importantes para a formação das pessoas, para o fortalecimento da democracia na sociedade e para o processo de 'cidadanização' dos que ali se encontram.

A sustentabilidade da instituição educativa aqui referida assenta-se em sua imprescindível inserção política na dinâmica da vida das pessoas, tantos nas dimensões públicas quanto privadas. A escola deve se constituir como um bem social comum, uma referência institucional para a comunidade na qual está inserida, construindo sua institucionalidade local a partir da corresponsabilidade entre Estado e Sociedade Civil e da forma a menos homogênea possível. Significa dizer que ela acaba agregando agentes sociais individuais ou institucionais, dotados de múltiplas intenções e interesses, muitas vezes conflituosos e mesmo excludentes, que se articulam entre si na configuração de um projeto pedagógico para a escola.

Essa abordagem extrapola o entendimento da sustentabilidade ecológica e ambiental relacionada estritamente ao meio ambiente físico natural, alcançando a sustentabilidade da escola como instituição que se organiza em torno da efetivação de sua função social, no caso aqui em discussão, a função protetiva em torno de vários elementos abordados ao longo deste texto. Quase nada tem sido discutido a partir dessa lógica, mas temos a intenção de aprofundar esse debate.

\footnotetext{
${ }^{3}$ Podemos considerar as seguintes dimensões de sustentabilidade: 1 . Sustentabilidade social: ancorada no princípio da equidade na distribuição de renda e de bens, no princípio da igualdade de direitos a dignidade humana e no princípio de solidariedade dos laços sociais. 2 . Sustentabilidade ecológica: ancorada no princípio da solidariedade com o planeta e suas riquezas e com a biosfera que o envolve. 3 . Sustentabilidade económica: avaliada a partir da sustentabilidade social propiciada pela organização da vida material. 4 . Sustentabilidade espacial: norteada pelo alcance de uma equanimidade nas relações inter-regionais e na distribuição populacional entre o rural/urbano e o urbano. 5. Sustentabilidade político-institucional: que representa um pré-requisito para a continuidade de qualquer curso de ação a longo prazo. 6. Sustentabilidade cultural: modulada pelo respeito à afirmação do local, do regional e do nacional, no contexto da padronização imposta pela globalização. (MINISTÉRIO DO MEIO AMBIENTE, 200, p. 42)
} 


\section{Promotora de formação continuada da comunidade educativa}

Esse aspecto diz respeito ao envolvimento de todo os componentes da realidade escolar, sejam ou não profissionais da educação. Processos de formação continuada precisam ser propostos por todos os que compõem e dão vida à escola no sentido de agregá-los como um grupo coeso que, apesar dos conflitos advindos das relações, atua em torno da efetivação da dignidade humana como princípio pedagógico.

Além dessa formação ampliada da comunidade educativa, o projeto pedagógico da instituição precisa, de forma objetiva, propor e executar um cronograma de formação continuada, para além das que ocorrem no período de planejamento pedagógico, cuja concepção pode ser embasada em Brzezinski (2008, p. 1144), que, a partir de Ferry (1987),

\footnotetext{
Destaca que a formação de professores possui uma natureza específica e apresenta particularmente três traços distintivos de qualquer outra formação: a) é uma dupla formação, pois, simultaneamente, é acadêmico-científica e pedagógica; b) é uma formação profissional, porquanto tem por finalidade formar pessoas que irão se dedicar à profissão-professor; c) constitui formação de formadores, porque se desenvolve em um espaço em que se realiza a formação de quem se forma ao mesmo tempo em que ocorre a prática profissional do formador.
}

Denota-se que a necessidade de formação continuada, nessa perspectiva, além de uma iniciativa técnica, de aperfeiçoamento da prática pedagógica e de fundamentação acadêmica docente, alcança uma estratégia de dimensionamento da ação humana dos professores no ambiente escolar, considerando a complexidade do ato de ensinar e do fenômeno educativo.

Trata-se de pensar a escola também como lugar que problematiza a ação docente e dos demais profissionais da educação, o lugar que esses atores ocupam na sociedade, a necessidade de valorização de sua ação e de sua autoestima, o resgate da sua identidade profissional, enfim, processos formativos contínuos que abordem todas as questões referentes aos conteúdos relativos ao ser agente profissional em um espaço que protege suas crianças e adolescentes.

\section{Intersetorial}

A escola, enquanto instituição educativa, precisa se articular organicamente com outras instituições da rede de proteção social, garantindo-a como espaço privilegiado de formação de crianças e adolescentes no sistema de garantia de direitos.

Já vimos anteriormente que a escola é instituição componente da rede de proteção social, juntamente com várias outras instituições, as quais, articuladas, conformam uma ação protetiva ao segmento infanto-juvenil. A noção do enredamento solidário e cooperativo das pessoas, 
representadas por instituições, é animadora e constitui a única possibilidade efetiva de se cuidar de crianças e adolescentes em uma sociedade tão complexa.

Redes - tema central deste caderno - é um conceito atual, que propõe uma inovação radical no modo de gestão social pública. Introduz novos valores, habilidades e processos necessários à condução do trabalho social numa realidade que é complexa. Não podemos mais atuar num ponto sem olhar para outros, somando e integrando competências e intervenções. A rede é um meio, um modo de representação das interrelações e conexões de como se expressa a complexidade. Não vivemos mais em uma sociedade simples. Não enfrentamos mais variáveis simples. Os fatos são multicausais e multidependentes entre si. A própria sociedade civil se comporta como uma 'sociedade-rede'. (GUARÁ, 2010, p. 8)

Trata-se de uma abordagem inovadora de concepção e gestão de políticas públicas, cuja efetividade depende de vários fatores, dentre os quais a construção do paradigma de que crianças e adolescentes são sujeitos de direito nos processos formativos dos profissionais que constituem a rede de proteção social e atuam na garantia do princípio da prioridade absoluta.

Essa inovação reside no fato de se introduzir uma também inovadora cultura e mentalidade no fazer da política pública, cuja principal característica está na horizontalização do poder, na valorização de ações autônomas, na compatibilização de tempos de agir diferenciados, na participação efetiva de atores diversos em torno de um objetivo comum. Nesse sentido,

\begin{abstract}
Comunicação e articulação são indispensáveis ao trabalho social em rede, pois costuram a oferta de oportunidades e de acesso a serviços e relações no território; conjugam e integram a população-alvo a uma cadeia de programas e serviços ligados entre si. A ação interprogramas permite potencializar o agir, porque retira cada ação do seu isolamento e assegura uma intervenção agregadora e includente. (GUARÁ, 2010, p. 9)
\end{abstract}

\title{
10 Produtora de capital social
}

A escola, enquanto ambiente de aprendizagem de valores democráticos, é produtora de capital social por meio do desenvolvimento de uma cultura cívica que fortalece laços de solidariedade e, como consequência, faz os sujeitos confiarem nas pessoas e nas instituições; dessa forma, contribuem para o desenvolvimento da capacidade associativa, da cooperação mútua, da construção de redes e de relações de reciprocidade.

Tal premissa atua em movimento contrário à percepção que as pessoas possuem sobre as tensões que afetam a atual ordem social e política, que leva a uma cultura de desconfiança e acaba por contribuir com o decréscimo da intensidade de democracia nas relações, relações nas quais há incontroverso desequilíbrio entre os princípios e as práticas de justiça e solidariedade entre as pessoas. Em sociedades caracterizadas pela baixa densidade democrática das relações 
e, consequentemente, das instituições públicas, ressaltam-se valores privados, devido à presença de relações paternalistas e patrimonialistas baseadas em troca de favores e benefícios, que não possibilitam o acesso igualitário a esferas de poder (PRÁ, 2006, p. 278).

Nesse tipo de cenário, não há espaço para a inclusão, para a valorização da diversidade e, portanto, para o desenvolvimento de culturas relacionais cujo conteúdo seja mais humanista e emancipador. Aqui situamos a construção da cultura de garantia e respeito aos direitos humanos. Nesse sentido, a escola como espaço de proteção social deve atuar como o lugar da construção da cidadania ativa e da cultura pública republicana e democrática.

\section{Considerações finais}

Defendemos que à escola cabe, na lógica aqui exposta, institucionalizar a capacidade de, no processo de formação de crianças e adolescentes que lá convivem, elevar o engajamento cidadão como conteúdo formativo de suas práticas pedagógicas, por meio de processos que ensinem e estimulem a participação de cidadãos em variadas instâncias organizacionais da sociedade civil. Tal diretiva permite gerar capital social como produto da formação cidadã que fomenta a dignidade humana, que mais adiante será uma habilidade estruturante na atuação desse indivíduo em sociedade, quer como cidadão, no exercício do controle social, quer como agente propositor de políticas públicas, como liderança política capaz de valorizar as instituições e as pessoas.

Entendemos essa 'nova' roupagem da escola enquanto ambiente protetivo como uma desafiadora proposição aos que estão na instituição, seja como profissionais da educação e comunidade educativa, seja de forma indireta como agentes formadores dos que fazem da escola seu ambiente laboral, como os professores universitários que formam professores.

A função social da escola, portanto, deve corresponder à formação da capacidade de intervenção de cada mulher e cada homem sobre sua própria vida, processo em que é essencial ampliar suas liberdades e tornar a política cada vez mais representativa das demandas sociais (TOURAINE, 1996, p. 51-52). À escola como espaço de proteção cumpre formar todos para que ocupem os espaços políticos e possam levar ao Estado suas demandas plurais como conteúdo das políticas públicas. Vemos essa possibilidade se realizar nos processos de formação da educação em direitos humanos.

Pensamos que temos feito pouco, logo, podemos fazer mais! Conhecer possibilidades de se fazer mais é o início, mas não garante a mudança. Paulo Freire, em seu livro Pedagogia da Esperança, aponta que "é preciso deixar claro, que, nos domínios das estruturas 
socioeconômicas, o conhecimento mais crítico da realidade, que adquirimos através do seu desvelamento, não opera, por si só, a mudança na realidade" (FREIRE, 1992, p. 32). Isso quer dizer que, embora tenhamos trilhado um caminho normativo importante - e tomara que irreversível -, no que se refere às condições de oferta da educação na atualidade, isso não é, por si, suficiente para que a escola se constitua, em corpo e alma, de forma diferente. Ainda há muito a percorrer.

\section{Referências}

ARENDT, Hannah. Entre o passado e o futuro. 5 ed. São Paulo: Perspectiva, 2005.

BOURDIEU, Pierre. Escritos de educação. Petrópolis, Vozes, 1998.

BRASIL. Lei de Diretrizes e Bases da Educação. Senado Federal, Brasília; 1996.

BRASIL. Plano Nacional de Educação em Direitos Humanos. Secretaria Especial dos Direitos Humanos - SEDH/PR, 2007.

BRZEZINSKI, Iria. Políticas contemporâneas de formação de professores para os anos iniciais do ensino fundamental. Revista Educação e Sociedade, Campinas, v. 29, n. 105, set./dez., p.1139-1166, 2008.

CAMPBELL, Selma Inês. Projeto político-pedagógico: guia prático. Rio de Janeiro: Wak Editora, 2010.

CASTRO, Adriana D.; LOPES, Roseli Esquerdo. A escola de tempo integral: desafios e possibilidades. Ensaio: aval. pol. públ. Educ., Rio de Janeiro, v. 19, n. 71, abr./jun., 2011. p. 259-282.

CUNHA, Luis Antonio. A educação brasileira na primeira onda laica: do Império à República. Rio de Janeiro: Edição do Autor, 2017.

CURY, Carlos Roberto Jamil. A gestão democrática na escola e o direito à educação. Revista Brasileira de Política e Administração da Educação, v. 23, set./dez., p. 483-495, 2005.

DALLARI, Dalmo de Abreu. Elementos de Teoria Geral do Estado. Editora Saraiva, 33 edição, 2016.

ESTÉVÃO, Carlos V. Educação, justiça e democracia: um estudo sobre as geografías da justiça em educação. São Paulo, Cortez, 2004.

FERRY, G. Le trajet de la formacion. Paris: Dunod, 1987.

FREIRE, Paulo. Pedagogia da esperança. Rio de Janeiro: Paz e Terra, 1992.

GALIAN, Cláudia Valentina; SAMPAIO, Maria das Mercês Ferreira. Educação em tempo integral: implicações para o currículo da escola básica. Currículo sem Fronteiras, v. 12, n. 2, maio/ago., 2012. p. 403-422. 
GENTILLI, Pablo; OLIVEIRA, Dalila. A procura da igualdade: dez anos de política educacional no Brasil. In: SADER, Emir (Org.). Lula e Dilma: 10 anos de governos pósneoliberais. São Paulo: Boitempo, 2013. p. 253-262.

GUARÁ, I. M. R. É imprescindível educar integralmente. Cadernos CENPEC, São Paulo, v. 1, n. 2, jul/dez, 2006. p.15-24.

LIMA, Max Fernando Silva; SILVEIRA, Rosa Maria Godoy. Educação em/para os direitos humanos: justificando os porquês. In: RECHEMBACH, Fabiana; ANDRADE, Fernando César Bezerra. Educação em Direitos Humanos: construindo políticas públicas. Curitiba: Editora CRV, 2016. p. 45-58.

MINISTÉRIO DO MEIO AMBIENTE. Ciência \& Tecnologia para o Desenvolvimento Sustentável. Brasília: Ministério do Meio Ambiente Brasília, 2000.

NEVES, Lúcia Maria Wanderley (org.). A nova pedagogia da hegemonia. Estratégias do capital para educar o consenso. São Paulo: Xamã, 2005.

POCHMANN, Márcio. Políticas Públicas e situação social na primeira década do século XXI. In: SADER, Emi (Org.). Lula e Dilma: 10 anos de governos pós-neoliberais no Brasil. São Paulo: Boitempo, 2013. p. 145-156.

PRÁ, Jussara Reis. Políticas Públicas, Direitos Humanos e Capital Social. In: BAQUERO, Marcello; CREMONESE, Dejalma. Capital Social: Teoria e Prática. Ijuí: Ed. Unijuí, 2006. p. 275-297.

PUTNAM, Robert D. Comunidade e democracia: a experiencia da Itália moderna. Rio de Janeiro: Fundação Getúlio Vargas, 1996.

RAYO, José Tuvilla. Educação em Direitos Humanos: ruma a uma perspectiva global. Porto Alegre: Artmed, 2004.

SILVA, Maria Salete. Democracia e Sujeito: uma relação indissociável na obra de Alain Touraine. Revista Emancipação, Ponta Grossa, v. 8, n., p. 21-34, 2008.

TOURAINE, Alain. Critique de la modernité. Paris: Fayard, 1992.

TOURAINE, Alain. Crítica da modernidade. Petrópolis: Vozes, 1994.

TOURAINE, Alain. O que é a democracia? 2 ed. Petrópolis: Vozes, 1996.

TOURAINE, Alain. Poderemos viver juntos? Iguais e diferentes. Petrópolis: Vozes, 1998. 